\title{
A PERCEPTUAL-COGNITIVE PROGRAM TO TRAIN SOCCER PLAYERS' DECISION MAKING
}

\author{
Julien Glaude-Roy, \& Sacha Stoloff \\ Department of Human Kinetics, Université du Québec à Trois-Rivières /Centre de recherche \\ interuniversitaire sur la formation et la profession d'enseignant (Canada)
}

\begin{abstract}
Elite sport is all about making the right decision, at the right time, under pressure and in any context (Vickers, 2007). Many tools are available to train decision-making skills. One used commonly in elite level sports is video feedback. However, with young players, this tool is rarely used due to time constraints and athlete-coach ratio. Nowadays, an alternative to video feedback is used in the form of a perceptual-cognitive exercise (Zentgraf, Heppe, \& Fleddermann, 2017). This exercise has significant effects on decision-making skills when used during warm-ups, but cumulative effects have not been measured (Holding, Meir, \& Shi, 2017). Also, perceptual-cognitive exercise has mainly been studied in experimental contexts, leaving few considerations for athletes and coaches' reality.

Therefore, this study aims to help a coach integrate perceptual-cognitive exercises in his training program. The first objective is to describe the clinical supervision process offered to a youth coach. Sub-objectives involve (a) understanding the different phases of the clinical supervision and (b) measuring players' performance as indication of change. The second objective is to describe players and coach's perceptions about quality and effectiveness of such program.

One female coach participated in the study, as did her 27 young female players $(M=12,25 \pm 0,28)$. They completed a six-week perceptual-cognitive program, twice a week. To jot down the supervision process, a log-book was used by the researcher during 16 weeks. Players' performance was measured with Stivi software for response time and decision accuracy during practice $(n=13)$. Decision accuracy in game was measured with observation grids, three times: week one, six, and three weeks post intervention. As for actors' perceptions, focus groups were used with players' $(\mathrm{n}=2 \mathrm{x} 8)$ and an individual semi-structured interview was used with the coach $(n=1)$.

Findings indicate that the clinical supervision process presents three phases. In the programming phase, results show that building sequences alone for perceptual-cognitive exercises is complex and time consuming, and thus unlikely to be attempted by the coach alone. In the interaction phase, the six week program was easily integrated to the training schedule. Also, the coach noted positive changes in her players, such as search for information at play and verbal support to partners holding the ball. Also, results show a slight decrease for response time and increase for decision accuracy. Finally, during the evaluation phase, performance measures enabled an objective analysis of advantages and limits of the proposed program.
\end{abstract}

Keywords: Clinical supervision, cognition, decision-making, perception, sport.

\section{Introduction}

Top athletes are those able to make the right decision, at the right time, under pressure and in any context (Vickers, 2007). One tool commonly used to coach decision-making skills in elite level sports is video feedback. However, time constraints and high athlete-coach ratios limit its use with younger athletes. Zentgraf, Heppe, and Fleddermann (2017) reviewed the effects of perceptual-cognitive exercises with the potential to replace video feedback. The exercises are done by watching short video clips of the sport trained, occluding the clip at a crucial moment and asking the athlete to make a decision as fast as possible. However, they aren't widely spread because of their lack of realism and considerations for retention and transfer of decision-making skills (Broadbent, Causer, Williams et Ford, 2015).

In the last 10 years, researchers have modified the exercise using different strategies. For example, Gabbett, Rubinoff, Thorbun, and Farrow (2007) coupled perception and action by adding a motor response to the exercise to successfully train anticipation skills of softball players. On the other 
hand, Hohmann, Obelöer, Schlapkohl, and Raab (2016) compared 3D images to 2D images with results on decision time and decision accuracy. Unfortunately, both strategies need large screens and complex equipment not easily accessible for youth coaches. Anyhow, Spittle, Kremer, and Hamilton (2010) showed that the size of the screen doesn't affect results on decision-making skills. Thus other strategies should be explored if to be used by youth coaches.

Recently, Lorains, Ball, and MacMahon (2013) improved decision-making skills of Australian football players by simply using above real-time video clips. Playing videos one and a half times faster appeared to be more "game like" than normal speed to the athletes. However, the strategy showed no effects with younger and less experienced athletes. Differently, Holding, Meir and Shi (2017) used the perceptual-cognitive exercise during warm-ups to train specific reactive-agility in rugby. Since cumulative effects have not been measured, effects of this strategy remain unclear.

\section{Conceptual framework and objectives}

To our understanding, no studies have worked with the coach to help him implement the perceptual-cognitive exercise in practice. For a coach, adding a new exercise to his training routine obliges him to change his practice. To this end, clinical supervision is known to have positive effects leading to transformative practice (Brunelle, Stoloff, Roy, Desbiens, \& Spallanzani, 2008; Stoloff, Spallanzani, \& Brunelle, 2016). Together a coach and a supervisor go over three phases of intervention: programming, interaction and evaluation (Brunelle, Drouin, Godbout et Tousignant, 1988). The programming phase includes context, program and omen variables used to plan the intervention. The interaction phase is the core of the intervention since the coach is in action, as well as his players. It includes all process variables. The evaluation phase is used to analyze the product of the intervention. Specifically, coach and supervisor evaluate the quality and the effectiveness of the practice put in place by the coach.

In sport, a coach's effectiveness is based on athlete's improvement, reflecting the level of learning. According to Schmidt (1993), learning is a result of practice and observed by a change in the athlete's performance. Those changes are then confirmed by skill retention and transfer (Schmidt, 1993). Retention is the ability to maintain a certain level of performance even after a prolonged pause in practice. Transfer is the ability to use the skills learned in different or new contexts. In sport, decision-making skills often use decision accuracy and response time to measure level of learning of perceptual-cognitive skills (Vickers, 2007). The skills learned during practice must then transfer to competition (Vickers, 2007).

Therefore, this study aims to help a coach integrate a perceptual-cognitive program during practice. The first objective is to describe the clinical supervision process offered to a youth coach. Sub-objectives involve (a) understanding the different phases of the clinical supervision and (b) measuring players' performance as indication of change. The second objective is to describe players' and coach's perceptions about quality and effectiveness of such program.

\section{Methods}

One female coach participated in the study, as did her 27 young female players $(\mathrm{M}=12,25 \pm 0,28)$. Being on two different teams, the players practiced together and played each other in regular season. They all completed a six-week perceptual-cognitive program, twice a week using Samsung Galaxy E Lite tablets. The program used was Stivi software, specifically built for this study, enabling perceptual-cognitive exercises on tablets without Wi-Fi connection for easy use on the field.

Done before practice, exercises consisted of 30 video clips, four to six second long, showing game footage of the two teams. Each video was occluded at a critical moment for decision-making. Players chose the decision they thought correct by clicking on boxes presented on the tablet's screen. They were instructed to do so as quickly as possible.

For all data collection, institutional ethics approval was provided (approval number CER-18-246-07.08), and informed consent was obtained from participants and their parents before the commencement of the study. To answer our first objective, a log-book (LB) was used to jot down the 16 weeks supervision process. As indication of change, athlete's decision accuracy and response time during practice were measured $(n=13)$. In addition, in-game decision accuracy was assessed with an observation grid related to passing, dribbling and shooting skills, coding 20 minutes episodes, during games between the two teams at three occasions: week one, six, and three weeks post intervention. To answer our second objective on actors' perceptions, focus groups $(\mathrm{FG})$ were used with players $(\mathrm{n}=2 \times 8)$ and an individual semi-structured interview (SSI) was used with the coach $(n=1)$. 
All quantitative data was collected though Stivi software, then analysed with SPSS24. ANOVA analysis of mean decision accuracy and response time during practice was used to describe changes for short-term learning and retention. To describe performance transfer to competition, ANOVA analysis related to proportional success of passes, dribbles and shots were used, allowing identification of changes in athlete's performance. All qualitative content was transcribed then analysed with InVivo10, by content categorization, then validated by triangulation from LB, FG and SSI throughout the intervention.

\section{Findings}

\subsection{Objective 1: Describe the clinical supervision process offered to a youth coach}

The programming phase represented one of planning and familiarisation of the perceptual-cognitive exercises. It combined three stages: 1) identification of decisions to be trained, 2) filming sessions and 3) the building of the video clips (approximately, 20 hours) needed for the perceptual-cognitive exercises (LB, p.1-3). Each stage was in collaboration with the coach, except the third one, which was driven by the supervisor who was accustomed with the occlusion technique. The coach validated the video clips to insure concordance with decisions trained. In this case, these were: decisions with the ball, decisions when regaining ball possession and first touch orientation of the ball (LB, p.1.). This phase was the longest phase of all and unlikely to be attempted by the coach alone (SSI, p.2).

The interaction phase enabled to apply and test the perceptual-cognitive program. Types of decision trained where chosen by the coach according to the goals set at every practice. In all, decisions with the ball were trained six times; decisions when regaining ball possession twice and first touch orientation five times (LB p.4-14.) Results show a slight increase for decision accuracy (Figure 1), averaging $44,8 \%$ for sessions 1 to 3 and $51,7 \%$ for sessions 10 to 12 . Simultaneously, results show decrease for response time (Figure 2) during intervention, averaging 4,607 seconds for sessions 1 to 3 and 3,893 seconds for sessions 10 to 12 .

Figure 1. Changes in mean decision accuracy during practice.

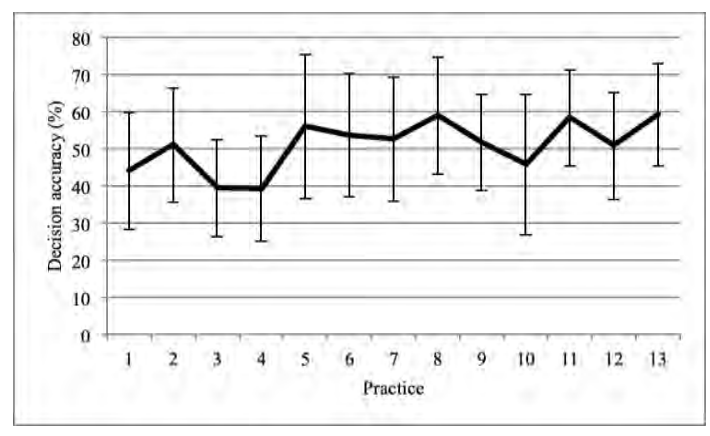

Figure 2. Changes in mean response time during practice.



Changes were found for in-game decision accuracy regarding dribbling with variation of efficiency $(61,9 \%>51,5 \%<63,3 \%)$, and regarding shooting skills, with an increase of efficiency $(15,4 \%<25,0 \%<41,7 \%)$ (Figure 3), compared to relatively stable performance for passing $(56,2 \%<59,1 \%<57,9 \%)$.

Figure 3. In-game decision accuracy for passing, dribbling and shooting skills.




Finally, the evaluation phase was one of reflection and critical thinking about the whole supervision process. It enabled analysis of advantages and limits of the proposed program, thanks to objective data concerning 1) general information (durations, effectiveness, 57,6\% of athlete's presence during intervention), 2) athletes' performance throughout the learning and retention phases, and 3) coach's ease in preparing and using such program.

\subsection{Objective 2: describe players and coach's perceptions about quality and effectiveness of the program}

Overall, as shown in table 1, the coach perceived positive changes in players' decision-making during and after the perceptual-cognitive program. Beyond those effects, she also perceived that the program was easily integrated to the training routine and acted as a modeling tool during training. In parallel, players perceived perceptual-cognitive exercise as beneficial for their performance on the field. Doing the exercises during warm-up allowed them to practice decision-making skills subsequently used on the field. The cognitive exercises helped them realize different errors they were making and inspired them to correct them during practice.

Table 1. Perceptions of coach and athletes threw the three phases of clinical supervision.

\begin{tabular}{|c|c|c|c|}
\hline Phase & Participant & Theme & Citing \\
\hline Programming & Coach & $\begin{array}{l}\text { Time } \\
\text { consuming }\end{array}$ & Way too many hours! SSI, p.2. \\
\hline \multirow{5}{*}{ Interaction } & \multirow{3}{*}{ Coach } & $\begin{array}{l}\text { Effect on the } \\
\text { players }\end{array}$ & $\begin{array}{l}\text { It's super interactive }[\ldots] \text {. It's like a game and they are clearly in } \\
\text { the generation for this. SSI, p.4. } \\
\text { Girls were able to challenge each other on their own. SSI, p.5. }\end{array}$ \\
\hline & & $\begin{array}{l}\text { Implantation } \\
\text { in training } \\
\text { routine }\end{array}$ & $\begin{array}{l}\text { Using the tablets didn't slow down the training routine. SSI, p. } 4 \text {. } \\
\text { With the tablets, they could do the exercise twice a week. If I } \\
\text { didn't have it, I would be happy to use video feedback once a } \\
\text { week or maybe every two weeks. SSI, p.3. }\end{array}$ \\
\hline & & Modeling & $\begin{array}{l}\text { They were able to associate both [training situations and } \\
\text { perceptual-perceptual-cognitive exercise] easily. SSI, p. } 3 \text {. } \\
\text { In terms of coaching, it was much easier because we had clear } \\
\text { examples. SSI, p.6. }\end{array}$ \\
\hline & \multirow[b]{2}{*}{ Players } & $\begin{array}{l}\text { Exercise } \\
\text { before } \\
\text { practice }\end{array}$ & $\begin{array}{l}\text { It allows you to practice what you just saw on the tablets. FG1, } \\
\text { p.3. } \\
\text { If we make errors during the exercise, we can correct them on } \\
\text { the field. FG2, p. } 2 \text {. }\end{array}$ \\
\hline & & Realization & $\begin{array}{l}\text { It's useful because it helps you learn from your errors. FG1, p.1. } \\
\text { When we use the tablets, we have time to think. Then we chose } \\
\text { how to apply it in the game. FG2, p.1. } \\
\text { Sometimes we don't know where to pass the ball. The tablet } \\
\text { helps us know. FG1, p.2. }\end{array}$ \\
\hline Evaluation & Coach & $\begin{array}{l}\text { Effect on the } \\
\text { players }\end{array}$ & $\begin{array}{l}\text { They think much more. They look around, they talk to each } \\
\text { other. SSI, p. } 6 \text {. } \\
\text { Girls lose the ball much less. Possession of the ball is much } \\
\text { better. SSI, p. } 7 \text {. }\end{array}$ \\
\hline
\end{tabular}

\section{Discussion and conclusion}

To our knowledge, this study is the first to focus on the process to implement a perceptualcognitive program with a youth coach, helping her to change her practice. This study was also the first to describe players' and coach's perceptions about quality and effectiveness of such program. The first objective (describe the clinical supervision process offered to the coach) showed that the programming of the perceptual-cognitive program is tedious, complicated and therefore unlikely to be attempted by the coach alone. Consequently, tasks such as filming and building of video clips should be taken on by a third party like consultants, federations or clubs.

Results during the interaction phase confirm that a perceptual-cognitive program can be easily integrated to players training routine. Perceptions of the coach and players where positive and don't show signs of resistance to change, such as observed by Brunelle and al. (2008) or Stoloff and al. (2016). This acceptance of change could be explained by the coach's perception of the exercise as a game, added to the level of implication of the supervisor in the programming phase making it more feasible. 
Variations in decision accuracy, response time and in-game decision accuracy were subtle, nevertheless interesting. Results concerning decision accuracy and response time remind us of the findings of Lorains and al. (2013) and Gorman and Farrow (2009), where results show similar effects for in-game decision accuracy. Presently, subtle variation for decision accuracy and response time during training could be explained by insufficient length of intervention or low level of athlete's attendance throughout the six week program mostly due to family vacations, inevitable considering athlete's age group and period of the year. In-game decision accuracy results would have been more significant with increased number of occurring events or observation time during matches. In line with Romeas and al. (2016), future research should consider using small-sided games, which augments the occurrence of dribbles, passes and shots.

During the evaluation phase, coach and players perceived that the program had a positive impact on the players' decision-making skills. Also, the exercise was time effective and easy to implement to the training routines. Therefore, the perceptual-cognitive program used during warm-ups seems a suitable and effective addition to video feedback in a youth coach's reality.

\section{References}

Broadbent, D. P., Causer, J., Williams, A. M., \& Ford, P. R. (2015). Perceptual-cognitive skill training and its transfer to expert performance in the field: Future research directions. European Journal of Sport Science, 15(4), 322-331.

Brunelle, J., Drouin, D., Godbout, P., \& Tousignant, M. (1988). La supervision de l'intervention en activité physique. Montreal, Qc.: Gaétan Morin.

Brunelle, J-P., Stoloff, S., Roy, M., Desbiens, J-F., \& Spallanzani, C. (2008). Étude de l'effet d'une stratégie de supervision clinique sur le processus de changement de pratique pédagogique d'un entraîneur. In N. Wallian, M.- P. Poggi, \& M. Musard (Éds), Co-construire des savoirs: les métiers de l'intervention dans les APSA (pp. 187-202). Besançon: Presses universitaires de FrancheComté.

Farahani, J. J., Javadi, A. H., O'Neill, B. V., \& Walsh, V. (2017). Effectiveness of above real-time training on decision-making in elite football: A dose-response investigation. Progress in Brain Research, 234, 101-116. doi:10.1016/bs.pbr.2017.08.007

Gabbett, T., Rubinoff, M., Thorburn, L., \& Farrow, D. (2007). Testing and training anticipation skills in softball fielders. International Journal of Sports Science \& Coaching, 2(1), 15-24.

García-González, L., Moreno, A., Gil, A., Moreno, M. P., \& Villar, F. D. (2014). Effects of decision training on decision making and performance in young tennis players: An Applied Research. Journal of Applied Sport Psychology, 26(4), 426-440.

Gorman, A. D., Farrow, D. (2009). Perceptual Training Using Explicit and Implicit Instructional Techniques: Does it Benefit Skilled Performers? International Journal of Sports Science \& Coaching, 4(2), 193-208.

Hohmann, T., Obelöer, H., Schlapkohl, N., \& Raab, M. (2016). Does training with 3D videos improve decision-making in team invasion sports? Journal of Sport Sciences. 34(8), 746-755.

Holding, R., Meir, R., \& Shi, Z. (2017). Can previewing sport-specific video influence reactive-agility response time? International Journal of Sports Physiology \& Performance, 12(2), 224-229.

Lorains, M., Ball, K., \& MacMahon, C. (2013). An above real-time training intervention for sport decision making. Psychology of Sport \& Exercise, 14(5), 670-674.

Romeas, T., Guldner, A., \& Faubert, J. (2016). 3D-Multiple Object Tracking task performance improves passing decision-making accuracy in soccer players. Psychology of Sport \& Exercise, 22(1), 1-9.

Schmidt, R. A. (1993). Apprentissage moteur: concepts et méthodes. In R.A., Schmidt, Apprentissage moteur et performance (pp. 167-188). Paris: Vigot.

Spittle, M., Kremer, P., \& Hamilton, J. (2010). The effect of screen size on video-based perceptual decision-making tasks in sport. International Journal of Sport \& Exercise Psychology, 8(4), 360-372.

Stoloff, S., Spallanzani, C., \& Brunelle, J.-P. (2016). Le cycle de Kolb appliqué à un processus de supervision pédagogique classique : perceptions des supervisés sur la formation de formateurs. Revue Approches Inductives, 3(1), 125-156.

Vickers, J. N. (2007). Perception, cognition, and decision training: the quiet eye in action. Champaign, Il.: Human Kinetics.

Zentgraf, K., Heppe, H., \& Fleddermann, M.-T. (2017). Training in interactive sports: A systematic review of practice and transfer effects of perceptual-cognitive training. German Journal of Exercise and Sport Research, 47(1), 2-14. doi:10.1007/s12662-017-0441- 